\title{
Género, poder y conocimiento. Para una biografía intelectual desde las ciencias sociales y la perspectiva de género
}

\author{
María Antonia GARCÍA DE LEÓN ÁLVAREZ \\ Universidad Complutense de Madrid \\ antonieta006@hotmail.com
}

Recibido: Marzo 2014

Aceptado: Mayo 2014

\section{RESUMEN}

La autora expone su trayectoria intelectual como socióloga y feminista. Ésta arranca de un contexto de espacio y de tiempo como fueron los últimos años del franquismo y el conocido fenómeno sociohistórico y político de la Transición española hacia la democracia (desde 1975 hasta 1982 aproximadamente). Entre los objetivos principales del texto están: 1) Mostrar un conocimiento en su contexto; 2) Analizar las influencias recibidas y sus causas (especialmente de la sociología francesa y del feminismo norteamericano); 3) Poner de manifiesto ciertos "problemas sin nombre" del conocimiento feminista; y 4) Promover el enfoque biográfico, poniendo el énfasis en esta especie de eslogan: lo personal es conocimiento. Dichos objetivos confluyen en tres, por un lado, un objetivo teórico: mostrar las determinaciones sociales de todo conocimiento, en nuestro caso, el binomio Género y Producción de conocimiento; por otro lado, un objetivo político y/o de acción: criticar y cambiar ciertos límites del conocimiento producido $\mathrm{y}$, en tercer lugar, hacer propuestas para una agenda feminista en el campo de las Ciencias Sociales y del Género.

Palabras clave: Biografía, poder, género, conocimiento, mujeres profesionales, feminismo, sociología.

Gender, power and knowledge. For an intellectual biography from the social sciences and the gender perspective

\begin{abstract}
The author exposes her intellectual trajectory as a sociologist and feminist. It starts from a context of space and time as were the last years of Francoism and the well-known sociohistorical and political phenomenon of the Spanish Transition towards democracy (from 1975 to 1982 approximately). Among the main objectives of the text are: 1) To show a knowledge in its context; 2) Analyze the influences received and their causes (especially French sociology and American feminism); 3) To highlight certain "unnamed problems" of feminist knowledge; And 4) Promote the biographical approach, putting the emphasis on this kind of
\end{abstract}


slogan: the personal is knowledge. These objectives converge in three, on the one hand, a theoretical objective: to show the social determinations of all knowledge, in our case, the binomial Gender and Knowledge production; On the other hand, a political and / or action objective: to criticize and to change certain limits of the produced knowledge and, third, to make proposals for a feminist agenda in the field of Social Sciences and of the Gender.

Keywords: Biography, power, gender, knowledge, professional women, feminism, sociology

\section{INTRODUCCIÓN}

Expondré algunos aspectos sobre la doble transición de las mujeres élites profesionales en España. Existe una cohorte generacional de mujeres (profesionales altamente cualificadas) que efectuaron una doble transición: la política y la personal. Es una generación interesante en la Transición y en transición, por el gran cambio social que experimentaron en sus propias vidas: educadas en el más rancio patriarcalismo franquista y en un país pobre y, sin embargo, ejerciendo hoy (décadas después) como mujeres profesionales de una sociedad avanzada y paritaria como es la española actual. Su éxito profesional constituye "per se" un fenómeno sociológico. Lo he investigado durante más de dos décadas de estudio sobre las mujeres élites profesionales españolas que comparten también rasgos internacionales.

A esta generación pertenecen las académicas (sociólogas, historiadoras, economistas, entre otras) que han producido un conocimiento desde la perspectiva de los estudios de género y han creado un nuevo campo científico, a finales de los años 80. Esta es mi generación, en ella contextualizo mi conocimiento, subrayando, no obstante, la singularidad de toda experiencia humana.

\section{CONTEXTOS HOSTILES}

Contextos hostiles es una buena forma de expresar el binomio tiempo/espacio vivido que en modo alguno exagera el entorno a la contra para el desarrollo de las mujeres españolas, tanto explícitamente, por una legislación restrictiva y discriminadora, como calladamente por indiferencia del medio hacia un destino que no fuera el matrimonio.

La dictadura franquista impuso como ideología y como práctica, el reino de la domesticidad. Las mujeres españolas fuimos intensamente socializadas familiar y escolarmente en él. De tal manera que podemos hablar de un refuerzo inusual de la domesticidad como objetivo vital de las mujeres, es decir, una especie de doble domesticidad: la tradicional que toda sociedad tiene bajo la influencia del patriarcado, y la impuesta a las mujeres por la dictadura. El ama de casa era el ideal de vida impuesto, modelo social dominante de lo femenino (como opuesto y negación al trabajo remunerado y fuera del hogar).

En dicho contexto, si se tenían los instrumentos culturales necesarios, más vivir en un medio urbano y antifranquista, era factible que te "naciera la conciencia". Esos 
eran los tres elementos "conditio sine qua non" para llegar a ser feminista, pero aun así, no era un camino ni fácil, ni probable. Ser feminista fue una opción muy minoritaria en el periodo referido arriba. Durante muchos años, el término feminista (al que se le solía añadir los términos de "rabiosa" o de "loca" entre otros, fue un duro peyorativo, incluso en el contexto de hombres marxistas, progresistas y antifranquistas, que no por ello, dejaban de ser mayoritariamente machistas.

Lanzando la vista hacia atrás, selecciono ciertos rasgos que, en mi opinión, son característicos de la posición existencial de mi generación. Ante todo, una primacía de la vida (vida, junto a conocimiento para entenderla). Ello marca una notable diferencia frente al eje existencial de la masculinidad. De este modo, si tuviera forzadamente que elegir tres rasgos serían:

1) Vida frente a Ideología, o lo que es igual, la entrega al existir femenino frente a la fascinación masculina por Leviatan, los partidos políticos y los "aparatos ideológicos de Estado", valga esta ironía althusseriana.

2) Derivado del anterior eje existencial: el espectro de intereses investigadores de las mujeres es más amplio y/o más "femenino" (como la vida misma). Las mujeres se diversifican frente al monolitismo masculino que el simple hecho de pensar en el poder (obsesionarse por obtenerlo) poda las ramas de la vida de los hombres, creándoles una visión monográfica de la vida: trabajo y a ser posible, poder, en cualquiera de sus vertientes. Evidentemente, estamos hablando de arquetipos de lo femenino/masculino, acentuados en la sociedad tradicional bajo el franquismo que significan una especializada división del trabajo y de la vida según género, en aquella sociedad española. Rasgos que aún continúan en parte, especialmente detectable en el reparto de la esfera del poder por género y en problemas relativos a la identidad de género.1

3) El encuentro con la Otra que operó el feminismo, para sectores cultivados de mujeres, las futuras profesionales (como movimiento de las clases medias cultivadas que era). Por fin, un sector de mujeres encontró un cauce para quebrar la tradicional enemistad que el Patriarcado cultiva sistemáticamente, "qua" sistema, entre las mujeres. Nos tuvimos que resocializar en una nueva amistad, la femenina; en síntesis, en una nueva visión del mundo; no fue tarea fácil; no éramos precisamente "corazones de nardo", tras un intenso modelaje en la femineidad patriarcal.

Frente a ese rasgo, los hombres no tuvieron que encontrarse con nadie, por así decirlo. No tuvieron que cambiar nada ni hacer experimentos sobre su propia identidad que sólo hoy comienzan tímidamente a repensarla. Sectores de mujeres hicimos una doble transición: la personal y la política; sectores de hombres, sólo hicieron una, la política. Si bien es cierto que el rasgo relacional inscrito en la dialéctica del género, acabó resocializándolos en el feminismo de sus mujeres.

\section{INVESTIGANDO MUJERES ÉLITES PROFESIONALES}

${ }^{1}$ Vid., por ejemplo, las mujeres individualizadas de la modernidad y su problemática en la obra
de Almudena Hernando (2012). La fantasía de la individualidad. Kazt ed. (Argentina/España) 
Las mujeres políticas han sido mi objeto de estudio, pero también empresarias, ingenieras, las "reales académicas", catedráticas, profesoras titulares de universidad, las élites "massmediáticas", entre otras, dedicándoles más de tres décadas de estudio.

A través de numerosas investigaciones de corte sociológico sobre las mujeres élites profesionales he elaborado un marco teórico que resumo con la siguiente paradoja: "élites discriminadas". Éste es, a su vez, el título de una obra mía. La expresión «élites discriminadas», quiere condensar un denominador común a todas estas mujeres profesionales de élite.

Dicho denominador común significa, que en términos generales, se produce en ellas: $1^{\circ}$ ) un fenómeno social que he analizado y diagnosticado como sobreselección social (es decir, una especie de «darwinismo social» para las mujeres); y $2^{\circ}$ ) un efecto correlativo a él: ser élites, pero ser élites discriminadas.

Deseo subrayar lo siguiente: 1) El difícil acceso al mundo profesional de la generación de mujeres (hoy entre 60-70 años) que constituyen el primer elenco relevante, en número, de primeras profesionales, lo anterior eran meras excepciones; y 2) Importantes aspectos biográficos de las élites femeninas que remiten a la entraña del patriarcado, pero también a las resistencias contra él.

He aquí lo que, traducido a lenguaje cinematográfico, he llamado, con una metáfora filmica, como el fenómeno "gender match point", recordando esa interesante secuencia con la cual arranca el film "Match Point" de W. Allen: ¿de qué lado caerá la pelota al chocar con el borde superior de la red? Triste que el destino social femenino fuera tan aleatorio y difícil, en una España nada lejana cronológicamente (pero sí mentalmente).

Paso ahora a lanzar una mirada sobre sus biografías. Tomamos las biografías de mujeres élites profesionales triunfantes, y desde ellas tendemos un hilo conductor hacia sus orígenes, o dicho de otro modo: recorremos una senda vital desde el hoy hasta el ayer (a modo de "flash back" cinematográfico). Recogemos y analizamos los factores determinantes de su éxito social. Subrayamos que es el anómalo éxito social de una muy cualificada y extraña minoría de mujeres que, casi milagrosamente, podríamos decir, logró prepararse para dicho éxito en el marco de una sociedad extremadamente patriarcal (y negadora de toda actividad profesional de la mujer) como fue la sociedad del periodo franquista en que se criaron. En dicha sociedad, se criaron cuales "hijas de Bernarda Alba" dicho al modo de arquetipo literario lorquiano. ¿Qué elementos vemos en sus biografias? Subrayo los datos siguientes:

Una estructura demográfica especialísima en la familia de origen: son muy frecuentes los casos de a) hijas únicas b) primogenitura femenina c) sororidades.

Los apoyos iniciales: es fundamental el apoyo paterno, el aliento del padre (o bien la "herida", una rabia histórico-freudiana que las ha encaminado hacia la rebelión: izquierda y feminismo.

Los apoyos adultos: es fundamental el encuentro de un esposo liberal que no trunque su carrera, sino que la potencie (dándose frecuentemente un fenómeno de clara homogamia social). Todo ello dentro de un potente contexto en el cual se van sumando 
"inputs". Ello construye, sin duda, una buena carrera profesional. Separaciones, divorcios son característicos episodios vitales posteriores.

Estas trayectorias femeninas reflejan la masa de recursos que moviliza cada biografía (capital económico, social, cultural, simbólico, es la terminología de los cuatro capitales de la Sociología de Pierre Bourdieu. Capital afectivo, muy significativamente para el caso de las mujeres, añado yo. "A sensu contrario", cabría deducir que hay una inmensa mayoría de mujeres que no han podido movilizar tantos y tales recursos (muy cualificados, además) y que se han quedado en el camino.

En la interesante lectura que la filósofa Celia Amorós hace de mi Obra en general, dice al respecto de lo que acabamos de analizar esa doble jugada (la del input paterno + el input del marido) va en contra de le ley de probabilidades. Es una combinación improbable. Pone de manifiesto los difíciles niveles probabilísticos en que nos movemos en las carreras profesionales y, en conclusión, nos instruye mucho acerca de cómo el poder está ligado a la masculinidad, cómo las mujeres lo ejercemos sin la completa investidura y cómo estamos expuestas a "la inmersión de status".

\section{EL PODER ES MEMORIA}

El poder es un tema genérico- trasversal, teórico, que puede arrojar sugerencias a un nivel de abstracción, pero también a un nivel de concreción, para quien sepa hacer las derivaciones pertinentes pues nada hay más práctico que una buena teoría.

El estudio del poder es un punto de partida ineludible para abordar todo tema de Género, es decir, es necesario arrancar desde la comprensión del fenómeno social del poder, ya que el Patriarcado es un sistema estructurado de poder por género. El poder es un tema clave en las Ciencias Sociales y cómo no en el desenvolvimiento de la vida social.

Desde la más suburbial chabola hasta el más lujoso "loft" neoyorquino podemos rastrear, tanto las micro-manifestaciones de la dominación masculina, como ir a sus macro-discriminaciones en las altas esferas.

Cualquier estudioso de Género debe comprender nada más adentrarse en las tareas de investigación, que va a enfrentarse con el fenómeno del poder y sus infinitas manifestaciones en la vida social y, asimismo, en los más variados cruces de clase, "habitat", raza, etnia o religión, por citar variables sociológicas clásicas.

Converge nuestra apreciación sobre el binomio poder y género con la de Kate Millet en el sentido de afirmar que la dominación masculina es una forma ingeniosa de colonización interior, más resistente que cualquier tipo de segregación, y más rigurosa y tenaz que la estratificación de clases. Es tal vez la ideología que más profundamente se halla arraigada en nuestra cultura por cristalizar en ella el concepto más elemental del poder.

No estamos subrayando ningún esencialismo sobre la masculinidad, sino un modo antropológico de ser, gestado en centurias de práctica social que aún pervive, y sin embargo está siendo lentamente erosionado por sociedades en pos de la igualdad de 
género. He ahí, tanto la palpitante actualidad del fenómeno, como lo crucial de su estudio.

Paso ahora a justificar mi elección de un objeto muy preciso de investigación, las mujeres élites profesionales (a las cuales he dedicado más de tres décadas de investigación sociológica) que a su vez mantiene sus cualidades generales, siendo un objeto de estudio concreto y amplio a la vez. Este objeto de estudio funciona como un eficaz test general de la permeabilidad o no de una sociedad hacia la igualdad de Género y, además, permite un estudio privilegiado sobre el fenómeno social del poder.

Haré un poco de reflexividad, tan querida a las CC. Sociales actuales y a modo de un "excursus" sobre mi obra:

Es un hecho extraño que, tras treinta años de investigación, el tedio no me haya sobrevenido (pregunta que me he hecho y me hago) yo que estoy tan abierta a muchos otros intereses. La respuesta es compleja y atañe a distintos niveles de lo profesional, social y biográfico. Miradas cruzadas, he escrito, quién investiga y qué investiga.

Con dichas expresiones aludo al largo proceso de hacerme auto consciente investigando (es decir, con el hecho de ir haciendo investigación). Atención, una forma de descolonización de los patrones dominantes cognitivos de Género. De tal manera que sucediera como si la investigación me interpelara, cobrando subjetividad y carne (he ido creciendo con ella). Me preguntara, me convenciera con sus pruebas, sus argumentos, en suma, con su valor fáctico aplastante, con su impactante cambio social. De todo, menos aburrido, podría decir. Este es un aliento notable contra el desaliento (valga este deliberado juego de palabras). Bajo la pregunta quién investiga, se encuentra también toda una temática que llamo de "cronos y conocimiento", un caro binomio para la historia de las disciplinas académicas, la reflexividad y temas relevantes para la Historia y la Sociología de las ciencias sociales, temas que tanto me interesan y están inscritos en mi obra. Cierro este excursus.

Prosigo con el análisis anterior. Al ser visto el fenómeno del poder desde la visión de la Otra (la que por natura no tiene poder en una sociedad patriarcal) podemos observar cómo la perspectiva de género instruye novedosamente sobre la naturaleza del poder. Dicho en frase rotunda: el Género enseña sobre el Poder.

Esta nueva mirada de género penetra mucho más el fenómeno, y aporta mucha más sustancia y matiz que el tradicional estudio sobre el poder: de corte formal, oficialista, público ("acartonado" podríamos decir) y, obviamente, androcéntrico.

Las mujeres en la Academia $^{2}$ (a la cual denomino Espacio-Espejismo) como en la política, y en otros ámbitos, funcionamos con muchos elementos del síndrome del parvenu, es decir, de las recién llegadas.

Celia Amorós, comenta ese fenómeno en el prólogo a mi última obra (2011):

\footnotetext{
${ }^{2}$ Uso el término academia en genérico, no referido a las Reales Academias, sobre las cuales dirigí una investigación en equipo, específica, llamada La excelencia científica, Instituto de la Mujer. Madrid, 2005.
} 
"Estamos al borde de la silla, no cómodamente repantigadas en un sillón. Para bien y para mal. Para mal, porque es como si ejerciéramos el poder sin la completa investidura: necesitamos dosis adicionales de refrendo masculino si es que queremos afianzarnos. Para bien, porque no ha habido tiempo para que los moldes academicistas en lo peor que tienen de escolasticismo nos hayan ahormado. De este modo, ganamos una perspectiva insólita: la de la orilla, que nos permite ver el horizonte, mientras que desde el centro (desde la posición dominante masculina) se está hasta tal punto embebido / encuadrado en el seno del poder que se ve poco".

El saber académico le debe al ingreso de una masa crítica consistente de mujeres en las Universidades, un efecto reflexivo cuyas consecuencias se nos vuelven cada vez más patentes.

Las élites profesionales de mujeres son, además de todo lo que acabamos de escribir, un objeto privilegiado de conocimiento y de crítica o denuncia social, porque constituyen una anomalía social en el seno de una Sociedad Patriarcal. Dicho más explícitamente, significan una doble trasgresión social: ser en la vida pública (alejadas de los roles de la domesticidad y maternidad) y estar en los círculos exclusivos de la masculinidad.

Sintetizando lo anterior: estamos ante un auténtico arsenal de mecanismos sociales a desentrañar (tanto individuales como colectivos, tanto de orden psíquico como de orden social) que se desata por el hecho de estar una mujer en los territorios y fronteras masculinos.

Acabo de poner el énfasis en lo que supone ser una minoría. Aún estamos en la Era de "la primera que...". Sería ésta la anomalía por excelencia, puesto que choca frontalmente con la naturaleza del Sistema Patriarcal, contra su "dictum" más esencial: una mujer no debe tener poder, o como se ha dicho tradicionalmente: no debe de estar en la esfera pública, debe de estar en su casa, en el espacio de la domesticidad.

En síntesis, la anomalía se hace más patente e injustificada cuanto más grande y cualificado es el capital humano femenino. Recordamos aquí, la opinión del clásico (vanguardista para su tiempo) J.S.Mill, de que en una sociedad igualitaria, la servidumbre femenina es el gran anacronismo.

Y servidumbre, añado yo, para aquí y para ahora, puede ser no desempeñar los niveles profesionales para los que estamos capacitadas las mujeres y tenemos un currículo de excelencia.

El mundo del poder informal que es el poder por excelencia. El que va directamente al bulto, el que no tiene que guardar normas de la meritocracia ni prácticamente de ninguna otra clase. Es una especie de poder fáctico, basado en la fuerza (normalmente del dinero en nuestras sociedades). Es una clase de poder antiguo que no da explicaciones, es un poder sin transparencia.

El núcleo de máximo poder, es un círculo de la masculinidad, prácticamente al cien por cien de su composición, con unos mecanismos específicos para reproducir el poder en las alturas: mecanismos discrecionales, "arbitrarios", de cooptación, "cargos de confianza", y todo un lenguaje "ad hoc" usado por el poder. 
Así pues, en sociedades democráticas, igualitarias, meritocráticas como ideario y normas formales-legales de funcionamiento, el círculo más alto del poder se comporta con pautas en las antípodas de ello y contradictorias con tal idiosincrasia racionalista. De ahí que, en este altísimo círculo de la sociedad, significativamente poder formal (sometido a normas) y poder informal (sin control ni visibilidad) pueda decirse que coinciden. He aquí un importante nudo de análisis.

Por todo lo que acabamos de observar, es fácil deducir que, en esos altos círculos, un androcentrismo selectivo y filtrador se incremente más aún, incluso de lo mucho que caracteriza ya otros círculos menos elevados.

Entre los fenómenos más característicos que he documentado está lo que he llamado "el viejo club de los muchachos" (cooptación sistemática de efectivos masculinos conocidos desde la infancia y/o juventud), amén de los "pactos entre caballeros".

Una ilustración relevante de lo que acabamos de escribir (y el lenguaje no engaña, trasluce la ideología) dice así: "Aspirantes al trono de la Complutense"3. Siendo ya una evidencia demostrada que cuanto más antigua es una Universidad más férrea es la red clientelista y de poder androcéntrico generado, de hecho, sólo en Universidades de reciente creación, alcanzaron las mujeres el rectorado (vr.gr.: la Univ. Pablo de Olavide)

"Ergo", dándose tales mecanismos exclusivistas de la masculinidad y excluyentes consciente o inconscientemente de las mujeres altas-profesionales, mantenemos que a las mujeres nos favorecen las reglas claras de la meritocracia (pese a no estar éstas exentas de problemas), nos beneficia la transparencia en el juego de lo social.

A modo de coda podríamos decir que el poder se comporta con singular aritmética: de forma directamente proporcional con los hombres y de forma inversamente proporcional con las mujeres, siguiendo sistemáticamente esta fórmula: a más poder, más hombres; a menos poder, más mujeres. Todo ello, se realiza a través de complejos mecanismos de dominación social y códigos de poder patriarcal.

\section{PARA UNA BIOGRAFÍA INTELECTUAL DE GÉNERO DESDE LAS CIENCIAS SOCIALES}

Mis primeras élites (1982). Cuando a finales de los años setenta, arribé al campo de las élites encontré una bibliografía española muy escasa en general y prácticamente inexistente para el caso de las mujeres. El marco de una Dictadura (El Franquismo, 1939-75) no era el más adecuado para reflexionar sobre el poder, las clases sociales y todo el aparato conceptual que conlleva el estudio de élites. Por otra parte, el marxismo que impregnaba las Ciencias Sociales (tal vez como el opuesto complementario a lo

\footnotetext{
${ }^{3}$ Se trata de las elecciones del rector Carrillo, con seis aspirantes, ni una sola mujer en una UCM pionera en los Estudios de Género, con un veterano Instifem y cientos de profesoras y catedráticas relevantes. Una observación importante: no ha habido aún ningún conato de candidatura de mujeres al Rectorado. El País, 30/V/2011.
} 
anterior) tampoco alimentaba el estudio de las élites y, por el contrario, propiciaba estudios de sectores desfavorecidos, clase obrera, movimiento sindical y temas similares, dentro del estrecho margen de permisividad de un Régimen "sin clases ni partidos" (como rezaba su ortodoxia). Años después, a través de la influencia y relación con la sociología de Pierre Bourdieu, con él y su equipo (mi estancia formativa en París) encontré una sociología que cultivaba un amplio abanico de temas, sin mostrar prejuicios ideológicos para estudiar los patronos franceses, o bien las prácticas deportivas de las élites, por ejemplo, demostrando una gran imaginación sociológica (ver, por ejemplo, los índices de su interesante revista "Actes de la Recherche en Sciences Socials"). Todo ello, fue sumamente estimulante para mí. Y sin duda, también fue muy importante para mi estar en relación con una de las más notables figuras de la sociológía (un clásico ya): Pierre Bourdieu, y su equipo: Monique de Saint Martin, Jean Claude Combessie, Remi Lenoir, entre otros brillantes sociólogos/as.4 Salir al extranjero era una especie de balón de oxígeno para quienes tuvieran inquietudes intelectuales; por otro lado, se obtenía un cierto sentido de permanencia (de pertenecer a una comunidad científica) puesto que una característica del trabajo intelectual en España era (y aún es) la soledad y la no abundancia de equipos, sobre todo en el campo de las Ciencias Sociales.

Lanzando la vista atrás, veo la pobreza intelectual en que vivíamos (en cuanto a medios) pero también la riqueza nuestra en el campo de lo político: en cuanto a interés, debate, crítica social, entrega. Éramos "la mejor juventud" como ha llamado a esa generación, homóloga en Italia, el conocido film de la RAI así titulado. Éramos la juventud "par excellence" para una época de transición social, éramos la juventud de la Transición Española. Recuerdo con qué interés leí y subrayé aquellos libros de la editorial argentina de nombre tan singular como era Amorrortu (siempre leí libros importados durante esos años desde Buenos Aires o desde México). Con entusiasmo adolescente leí aquellos tomos básicos de los universalmente famosos Berger y Luckmann (1968), el archiestudiado en España Bottomore (1963), idem Zeitlin (1968) y Nisbet (1976). También leí al inevitable C.W. Mills (1957). Por último, una fuerte ración de marxismo o filomarxismo, obligado según el gusto de la época e importante para la reflexión sobre el binomio élites/clases: Bertaux (1977), Bourdieu (1977), Laurin-Frenette (1976) entre no muchos más. Respecto a los libros sobre mujeres de corte sociológico, el listado era corto e indefectiblemente reiterado: Scanlon (1976) y, en clásico, Simmel (1925), entre otros pocos.

Hablando desde el punto de vista de la literatura feminista, si levantáramos la cartografía intelectual de la época (los mapas de nuestras bibliotecas individuales que serían como sumandos de una Biblioteca de Época) observaríamos sus más que notables semejanzas, claro está en un medio estudiantil antifranquista, progresista y feminista. Qué objeto de estudio tan seductor es la biblioteca estándar de una mujer feminista de la época. Qué posibilidad preciosa de ver qué circulaba por nuestras mentes, qué calentaba nuestros corazones. Son trabajos intelectuales finos, sofisticados que requieren una acumulación intelectual. Son éstos trabajos poco frecuentes en las Cc. Sociales españolas, proclives a los llamados problemas sociales más que a temas

${ }^{4}$ La dominación masculina, Bourdieu se hace eco de mi obra Elites Discriminadas. 
tratados desde la perspectiva de la Reflexividad por razones complejas que he desarrollado (García de León: 2007).

En mi estudio "Cincuenta años de bibliografía sobre las mujeres en España, 19401990" (1992) tuve la ocasión de comprobar ese dato: muchas mujeres-colegas habían leído exactamente los mismos libros que eran los que eran. Ello me dio la medida de la exactitud de mi observación, la cual no era difícil, dado lo parco del medio. Ahora bien, analizando comparativamente otras bibliografías, observo y destaco el siguiente rasgo: el internacionalismo del movimiento feminista hace que toda una generación de mujeres de los más variados países en el mundo occidental, hayamos tenido el mismo fondo común de lecturas; así estos son nombres que se repiten indefectiblemente: Kate Millet, Shulamith Firestone, Germaine Greer, entre otras pocas. "Last but no least", sobre este aspecto tan relevante para el conocimiento como es las fuentes en que nos nutrimos, destaco el fenómeno del anglocentrismo bibliográfico (y cultural, obviamente) tanto en aquellas décadas de mi formación como en la actualidad.

En cuanto a la debilidad de la bibliografía de género, en general, fue muy bien diagnosticada por M. Perrot (1986) y publicada en Annales. La resumo muy brevemente: su predilección sistemática por el estudio de la sexualidad-maternidad y similares, su obsesión por la dialéctica de la opresión, su inflación de estudios normativos, entre otras debilidades que señaló dicha autora. Tales debilidades fueron, en mi caso, sentidas en fechas tempranas, como pesados y aburridos tópicos, muchas veces consignas de un Movimiento Social, el feminismo, que como tales consignas eran muy válidas y respetables para la acción social pero muy poco estimulantes para el conocimiento. Huyendo del victimismo, del esencialismo, del voluntarismo, del psicologismo, y de otros bastantes "ismos" que impregnaban fuertemente los "Estudios de la Mujer", como se les llamaba en la época, busqué un colectivo privilegiado, las mujeres élites profesionales que, en principio, no tuviera tanto motivo de queja social.

Con el conocido dicho, de ser nosotras sujetos y objetos a la vez de investigación, hago hincapié en que tenemos una posición privilegiada, mi generación de científicas sociales, para hacer una doble arqueología de género, en este sentido: cambio de lo femenino/masculino y cambio de los Estudios de Género. Hemos visto cómo iban transformándose nuestras identidades interiormente $\mathrm{y}$ en cuanto a identidades reflejadas por lo social (igualmente en la masculinidad, aunque en menor medida). Igualmente, hemos visto cómo aquellos escritos de agitación feminista se iban convirtiendo en literatura de corte científico. Así en un tiempo relativamente breve, hemos pasado del panfleto a la academia, y este cambio ha sido apasionante en lo humano y de sumo interés epistemológico y disciplinar.

De ahí mi llamada al memorialismo de género y a la Reflexividad que hago en este texto. Nosotras vivimos la oscuridad (no obstante, llena de la luz vital de la Transición) de la larga noche del franquismo para las mujeres, dicho en esta especie de metáfora de género. Es mucha la Historia que podemos contar y escribir. Por otro lado, este quehacer que propongo enriquece la historia de las disciplinas académicas (vr. gr.: conocer el momento y el grado con el que incorporan o no la perspectiva de género) nutre la sociología del conocimiento y proporciona datos para una metasociología. Todos ellos frutos raros y escasos en una sociología como la española que quizás aún 
no haya alcanzado el grado de sofisticación que éstos requieren.

El mundo es el laboratorio de las Ciencias Sociales y está lleno de temas y asuntos, objetos sociales que bien construidos pueden dar lugar a notables investigaciones. Pero otra posibilidad de investigar es la de buscar en el propio escenario académico-profesional el objeto de estudio (tan social como cualquier otro). Todo ello constituiría un largo e interesante capítulo acerca del temperamento, ideología del investigador, a veces el género, la clase social, etc. de lo cual me he ocupado en otros trabajos. Asimismo, la larga línea de investigación que he sostenido durante años, sobre las élites profesionales femeninas tiene esas connotaciones de la Reflexividad, puesto que en general, he estudiado mujeres profesionales de mi generación, muchas de las cuales conozco personalmente, con lo cual he hecho práctico el consejo bourdiano: "saque usted de su propia experiencia".

Este trabajar sobre el propio campo, esta singular elección de objeto, tiene la ventaja de tener ya una acumulación de observaciones, de conocer muy bien el terreno, de desenvolverse cada día en él. La crítica tópica a este tipo de estudios es la consabida acusación de etnocentrismo-narcisismo, etc. Crítica desde mi punto de vista miope, pues el conocimiento del campo académico puede sobrepasar el mero conocimiento de un grupo profesional y dar cuenta de cómo se crea y transmite el propio conocimiento (además de enlazar ello con estructuras y contenidos de una institución tan crucial en nuestras sociedades como es el Sistema de Enseñanza.)

Asimismo, la reflexión (y la Reflexividad5, corriente emergente en las Cc. Sociales) sobre u na producción intelectual puede ayudar a crear balances y una agenda (en cierto modo es una investigación-acción) al modo de señalar cuestiones tan relevantes para nuestro trabajo como las siguientes: hitos alcanzados, fallos, lagunas, y derroteros a seguir. En síntesis, este tipo de investigación puede lograr levantar una cartografia intelectual del campo.

Ofrecemos una definición de Reflexividad según Rosanna Herz una de sus más destacadas especialistas:"La Reflexividad puede ser considerada como una forma de abrir el camino a una conciencia más radical de sí mismo de cara a la dimensión política del campo de investigación y para la construcción del conocimiento. La Reflexividad llega a ser un modo continuo de autoanálisis y de conciencia política."

Sin embargo, son muy escasos los trabajos "reflexivos" por así llamarlos que podemos encontrar en las Cc. Sociales españolas en general y asimismo muy escasos los trabajos "reflexivos" en el campo de los Estudios de Género (Pilar Ballarín, Celia Valiente, Isabel de la Torre, Teresa Ortiz, Teresa Torns, entre otras pocas).

Las causas de esta escasez de productos desde la perspectiva de la Reflexividad en y sobre las Ciencias Sociales (y sobre los Estudios de Género) son muchas y

\footnotetext{
${ }^{5}$ R. Hertz en su gran obra colectiva Reflexivity\&Voice (1997) nos da la que es en su opinión "the best definition of reflexivity I have found (Callaways's(1992): "Reflesivity can be seen as opening the way to a more radical conciousness of self in facing the political dimensions of fieldwork and constructing Knowledge(..) Reflexivity becomes a continuing mode of selfanalysis and political awareness" (p. VIII, op. Cit.)
} 
complejas; no procede hacer un análisis de ellas aquí.

\section{BUSCANDO OTROS HORIZONTES (INFLUENCIAS INTELECTUALES)}

La vida universitaria-académica española me parecía poco estimulante como ambiente intelectual. Como tantos otros jóvenes profesores decidí salir afuera6. Primero a París (como ya he escrito) después ir a Norteamérica se convirtió en un objetivo prioritario. Desde aquel lejano 1988, como "visiting scholar" en la Universidad de California San Diego (UCSD) hasta la actualidad, son bastantes las veces que he trabajado en los magníficas universidades y bibliotecas norteamericanas tanto de la costa Oeste como de la costa Este. Mi influencia de las interesantes autoras feministas y sociólogas norteamericanas es grande ¿Que admiro de su obra?:

1) La libertad tanto de sus objetos de investigación, como la libertad de títulos, estilos expresivos, etc. Todo ello queda realzado por contraste con el ambiente muy formal y encorsetado de las Cc. Sociales españolas de la época, incluidas las investigaciones feministas.

2) Por otro lado, el aliento optimista del Nuevo Mundo: todo es posible. Por ejemplo, la existencia de lugares universitarios productores de élites femeninas y militantes en pro del liderazgo femenino, como Wellesley College (Ma) donde estuve un curso y donde me di cuenta posteriormente que experimentaba gozosamente una resocialización feminista, incluso por ósmosis (por ejemplo, siempre que trabajaba en la Library estaba rodeada de todas las presidentas del College, cuyos retratos pendían de las paredes, visibilizando sus personas).

3) El respeto y el amor por su historia feminista (y, en general). Por ejemplo, en los años 80 ya tenían archivados con gran lujo de recursos todos los panfletos de las Women's Lib, del 68 y de loS 70. Este rasgo marca un gran contraste con la situación española, donde hay una especie de "horror por lo antiguo" y el riesgo de destrucción de documentos y archivos está siempre presente.

Todo lo anterior, me parece sumamente admirable del medio científico norteamericano, dotado de una fuerte comunidad científica y de un gran soporte económico Descendiendo a aspectos más concretos, me focalice sobre todo en el estudio de la biografía de científicas sociales que paso a mostrar no exhaustivamente.

En Ciencias Sociales, y dentro de la bibliografía anglosajona, son notables las voces de rescate histórico-biográfico, del cual hemos tratado. Hay sobresalientes autoras que desde la perspectiva de género (mezclando género y sociología) están llevando a cabo este importante trabajo intelectual así lo confirmaba hace tiempo la inglesa Mary Evans (en una obra traducida tempranamente al español): "A lo largo de los años 70 y 80 llegó a ser un lugar común para los investigadores describirse y

${ }^{6}$ Por sólo citar un ejemplo y anotar un In Memoriam, este es el caso del profesor Enrique Laraña, fallecido en el 2014 que estuvo por aquellos años en la Universidad de California, con el sociólogo Aaron Cicourel, como en mi caso. 
situarse a sí mismos tanto como al objeto de su investigación. Con este enfoque, en el que la identidad del autor se hacía explícita, se hacía la afirmación de la legitimidad de la autobiografía y biografía."7

Contrariamente a lo anterior, existe un cierto vacío al respecto en las Cc. Sociales españolas que afecta no sólo al caso de sus cultivadoras. De ahí que descienda a niveles tan concretos como seleccionar y explicitar títulos en la bibliografía final y "ad hoc" para este tema y de subrayar aspectos que me parecen cruciales para los Estudios de Género en España. Entre estos aspectos figuran los siguientes:

$1^{\circ}$ ) Rescate y fijación de autoras y su obra en el plano individual.

$\left.2^{\circ}\right)$ Evitar la invisibilidad en el presente y olvido en el futuro de ellas

$\left.3^{\circ}\right)$ Las múltiples biografías de autoras feministas, cual sumandos, facilitan una síntesis y una visión de conjunto del campo científico en que se desenvuelven y plasman la contribución realizada tanto individual como colectivamente.

$4^{\circ}$ ) Todo ello es un factor fundamental de socialización profesional para nuevas generaciones de científicas sociales.

$5^{\circ}$ ) Es una contribución a la historia general de la disciplina en su conjunto. siguientes:

Dando ejemplos (que obviamente me han influenciado y promuevo) reseño los

1) La introducción de Deegan (1991) es una interesante perspectiva histórica de la disciplina, contada y contando con las sociólogas. Hay, en ella, un análisis para una epistemología de género que proporciona sugerencias inestimables para futuras investigaciones ("women's issues" frente a "men's topics"...). Prácticamente casi no hay nada similar en la sociología española.

2) Más allá de estos apartados concretos de la obra de Deegan, lo que me impresiona (y conmueve) es el coraje y la voluntad de hacer Historia con un aliento feminista (vr. gr.: capítulos y tablas con estos contenidos: "founding sisters" que fueron Presidentas de la American Sociological Association.).

3) La obra colectiva de las sociólogas de la prestigiosa Universidad de Berkley, de 1994. Es de interés, por sólo citar un ejemplo, la conveniencia de expresarse, de conocerse, de intercambiar experiencias profesionales y vitales entre ellas y sus lectores/as que enfatiza la prestigiosa Arlie Hochschild, por tratarse de una especie de élite femenina aislada equidistante tanto del mundo de los hombres de la profesión como del mundo de la domesticidad en general.

4) La obra de Bárbara Laslett y Barrie Thorne (1997). Esta obra colectiva, a diferencia de las dos anteriores que eran en forma de diccionarios bio-bibliográficos y críticos, es un conjunto de once artículos de destacadas sociólogas. Se trata de contribuciones teóricas de la escritura autobiográfica a la sociología del conocimiento

${ }^{7}$ Mary Evans, Introducción al pensamiento feminista contemporáneo, Minerva Ed. Madrid, 1997 
y a la teoría social, incluyendo la contribución del feminismo "to the crafting and use of life histories as a genre".

5) La obra colectiva de Ann Goetting y Sarah Fenstermaker (1995). Hay que destacar en esta notable y voluminosa obra que incluye una valiosa selección de dieciocho significativos artículos (uniendo vida y sociología) la introducción teórica y conclusión de sus editoras, respectivamente Ann Goetting ("Fictions of the Self") y Sarah Fenstermaker ("Editing" women, memoir, and the sociological "I"). Goetting realiza una síntesis sobre las aportaciones de la biografía de mujeres que abreviadamente reflejamos aquí. La biografía cubre las siguientes lagunas, según las autoras citadas, en la literatura sociológica: (a) "Sensitive insight and confirmed connectedness, (b) Knowledge gaps, (c) The intersection of Micro and Macro, (d) Women's biography can contribute to the correction of the women's obscurity within the academy and within the discipline of sociology".

6) Our studies, ourselves: sociologists' lives and work / Oxford; New York:Oxford University Press, 2003 (la cual es un indicador de la continuidad de este tópico intelectual y bibliográfico). Figuran veintidós textos de famosas sociólogas norteamericanas. Otro dato: los nombres y autores se repiten sistemática y expresivamente en esta línea de producción bibliográfica. De este modo, contribuyen a la obra destacados nombres de la sociología norteamericana, como son: Dorothy E. Smith, Cynthia F. Epstein, Barrie Thorne, Susan A. Ostrander, Rosanna Hertz, Verta Taylor, entre otros. Las cuestiones centrales que tratan de responder todos los capítulos de esta obra son las siguientes: How much does personal biography matter in research? How much does a person's research matter to her biography? La obra tiene una clara intención de compromiso y cambio con la disciplina. Sobre la biografía, y como mero ejemplo, Dorothy Smith afirma que su misión is to change her own profession of sociology. She urges sociologists to explore how the self and society exist within texts.

7) Delamont, Sara. Feminist sociology (2003). Esta obra de la conocida socióloga británica Delamont, es imprescindible para los temas que he tratado. La obra incluye importantes reflexiones sobre la autobiografia.

Como síntesis final al respecto de lo que acabamos de tratar, si toda biografía de un científico es de gran interés, puesto que puede revelar claves del y para el conocimiento, las biografías de las mujeres científicas pueden constituir una epistemología de género, a la vez que lo anterior (doble relevancia, en cierta manera).

En todo lo anterior hay luces y sombras. De las luces admirativas ya he hablado; de las sombras, quiero destacar la siguiente: el enorme etnocentrismo de la literatura de Género Norteaméricana (y anglosajona, en general). Sólo lo escrito en inglés existe. Sólo se leen entre sí las autoras anglosajonas, con total ignorancia de la interesante producción en español de muy relevantes feministas como: Amelia Varcarcel, Celia Amorós, las mexicanas Marcela Lagarde o Marta Lamas, entre otras muchas notables que podría citar.

Trabajando con equipos internacionales. Este preciso objeto, mujeres élites profesionales, ocupa a un relativo reducido número de especialistas. Hay un cierto 
acuerdo sobre esta apreciación, entre ellos. No obstante, hay a veces fronteras difusas, por ejemplo, con el muy estudiado en la actualidad binomio de Género y Poder

La primera especialista que conocí al respecto, fue Cynthia Fuchs Epstein, una de las pocas mujeres que ha llegado a ser presidenta de la American Sociological Association. De ella es una muy temprana comparación internacional entre elites femeninas (1981)

Igualmente larga en el tiempo, es mi colaboración con uno de los no muy abundantes varones especialistas en género (y además en élites femeninas) Mino Vianello (Universitá de la Sapienza, Roma). El dirigió con enorme esfuerzo y éxito una investigación comparada de élites femeninas en veintisiete países industrializados y con igual número de investigadoras principales Su trabajo fue codirigido con Gwen Moore (Albany University).

\section{PROBLEMAS Y PERSPECTIVAS}

Las académicas y las científicas sociales han sido investigaciones mías recurrentes y prioritarias y objetivo propuesto a la agenda feminista colectiva. Esta línea de investigación tiene el siguiente "leit motiv": rescatar la aportación de dichas profesionales al acervo de las Cc. Sociales en España. Trazar genealogías y herencias científicas entre nosotras.

Nominar es fundamental (da fundamento). Dar nombres a los problemas y consignarlos. Pues bien, todos estos actos remiten al poder, asunto central en el mundo social, como dijera Weber, y de nuestro quehacer científico "per se". En palabras de Amelia Valcárcel subrayo este asunto crucial: "el poder es memoria. En realidad, el poder consiste en imponer tu propia memoria como la memoria significativa. Si no tienes poder, tu capacidad de fundar un relato y que ese sea pertinente, no existe."8

Nuestras sociedades producen esta norma no escrita pero eficaz: con cargo sí hay historia, sin cargo no hay historia; pero las mujeres no tenían cargos, así pues, las mujeres no tenemos historia. Ésta es la elipsis sistemática que hemos visto hacer y vemos hoy. Un buen ejemplo: en los fastos académicos veraniegos se conmemora la Transición española en el marco de gran lujo e influencia mediática de una famosa universidad. ¿Quiénes son los ponentes invitados? Quienes tuvieron cargos: los hombres. Este es el filtrado oficialista de la historia y la visión que cristaliza: la visión de los vencedores (parafraseando la obra de León Portilla, Visión de los vencidos). Pero con esta ancestral-actual poda, por así llamarla, la historia es mutilada sistemáticamente, queda alienada y cosificada en una única, incompleta e inexacta versión que sin embargo es la que pasa como legado y se reproduce con tales características hacia el futuro.

Un importante matiz a dicha necesidad de relato, de memoria, de transmisión, la enuncia y añade Amelia Valcárcel. En el contexto de una sociedad androcéntrica, y con el eje memoria/poder actuando como una gran elipsis sobre las mujeres y sus obras, 
parece tener fundamento lo siguiente: "la autoridad femenina se transmite por canales femeninos. Tenemos que hacernos presentes, aunque sólo sea en honor de la verdad"”.

En nuestro caso, crear genealogías de y en nuestros saberes es crucial tanto por el momento constituyente de los mismos que vivimos como por la constitución de un legado. La situación está madura para este doble momento constituyente. Todo ello guarda relación con unas élites académicas, mujeres científicas de excelencia que deben ser mencionadas y reconocidas, igualmente su saber en forma de herencia y/o tradiciones intelectuales a crear.

Es necesario dar nombre a los problemas, siguiendo la tradición de Betty Friedan que nominó al problema sin nombre, como escribiera ella (la alienación del ama de casa). El problema de hoy sí tiene nombre: el poder de las mujeres, en los términos y proporción definidos por la paridad.

El trabajo de una agenda feminista, hoy (dentro del contexto específico que he estado ilustrando de Género y Ciencias Sociales, o mujeres académicas dicho este término en genérico) lo expreso en estas tres tareas de investigación a realizar: balance, legado y herederas/os. Dicho de otro modo:1) hacer una aproximación al campo disciplinar ligada a la Reflexividad (balance) 2) una aproximación genealógica (legado) y 3 ) una aproximación biográfica (herederas/os).

Nuestra maestría, como generación interesante (que pasó la doble transición ya mencionada) radica hoy en esas tareas cruciales.

\section{REFERENCIAS BIBLIOGRÁFICAS}

ALBERDI, INES y GARCÍA DE LEÓN, M. ANTONIA (1990): Sociology of women, en Sociology in Spain, CSIC, Madrid, 1990.

ANDERSON, LINDA (1997): Women and autobiography in the twentieth century: remembered futures. London, New York: Prentice Hall/Harvester Wheatsheaf.

BERGER, BENNET B. (1990): Authors in their own lives: intellectual autobiographies. Berkeley: Berkeley University Press (Nota: versión española (1993) La Sociología como Profesión: Autobiografía Intelectual de veinte sociólogos americanos. Madrid: Ministerio de Trabajo y Seguridad Social.

BURGAN, MARY (2006): What ever happened to the faculty? Drift and decision in higher education. Baltimore, Md.: Johns Hopkins University Press.

BUTLER, JUDITH P. (1990): Gender trouble: feminism and the subversion of identity. New York: Routledge.

\footnotetext{
${ }^{9}$ Ibídem: Entrevista. Valcárcel se nuestra aquí de acuerdo con esa propuesta del feminismo de la diferencia.
} 
DELAMONT, SARA (2003): Feminist sociology. London: Thousand Oaks.

GARCÍA DE LEÓN, M. ANTONIA (1994): Elites Discriminadas. Barcelona: Anthropos.

GARCÍA DE LEÓN, M. ANTONIA (2002): Herederas y Heridas. Madrid: Feminismos, Cátedra.

GARCÍA DE LEÓN, M. ANTONIA (2005): La excelencia científica. Hombres y mujeres en las Reales Academias. Madrid: Instituto de la Mujer, Serie Estudios, N.88.

GARCÍA DE LEÓN, M. ANTONIA (2008): Rebeldes Ilustradas. La Otra Transición. Barcelona: Anthropos.

GARCÍA DE LEÓN, M. ANTONIA (2009): Antropólogas, politólogas y sociólogas. España y México: Plaza y Valdés.

GARCÍA DE LEÓN, M. ANTONIA (2011): Cabeza moderna/Corazón patriarcal. Barcelona: Anthropos.

GARCÍA DE LEÓN, M. ANTONIA y GARCÍA DE CORTÁZAR, MARISA (Coord.) (2001): Las Académicas. Profesorado Universitario y Género. Madrid: Instituto de la Mujer.

GARDASDÓTTIR, HÓLMFRÍDUR (2006): Latin America women as a moving force. Göteburg: Haina.

GILMORE, LEIGH (1994): Autobiographics. A feminist theory of women selfrepresentation. Cornell University Press.

HALLEY, JANET E. (2006): Split decisions: how and why to take a break from feminism / Princeton, N.J.: Princeton University Press.

HEILBRUN, CAROLYN G. (1989): Writing a woman's life. New York: Ballantine Books.

HERNANDO, ALMUDENA (2012): La fantasía de la individualidad. Argentina/España: Kazt.

LEGGOTT, SARAH (2001): History and autobiography in contemporary Spanish women's testimonial writings. Lewiston: The Edwin Mellen Press.

MILLER, NANCY K. (1988): Subject to change: reading feminist writing. New York: Columbia University Press. 
MILLER, NANCY K. (1991): Getting personal: feminist occasions and other autobiographical acts. New York: Routledge.

MILLER, NANCY K. (2002): But enough about me: why we read other people's lives. New York: Columbia University Press.

RISHOI, CHRISTY (2003): From girl to woman: American women's coming-of-age narratives. Albany: State University of New York Press.

SHOWALTER, ELAINE (2001): Inventing herself: claiming a feminist intellectual heritage. New York: Scribner.

SIEGEL, KRISTI (1999): Women's autobiographies, culture, feminism. New York: Peter Lang.

SMITH, SIDONIE (2001): Reading autobiography: a guide for interpreting life narratives. Minneapolis: University of Minnesota Press.

V.V. A.A. (1996): Getting a life: everyday uses of autobiography. Minneapolis: University of Minnesota Press.

V.V. A.A. (1989): Interpreting women's lives: feminist theory and personal narratives. Bloomington: Indiana University Press.

V.V. A.A. (1990): Feminist knowledge. Critique and construct London, New York: Routledge.

V.V. A.A. (1991): Women in sociology: a bio-bibliographical sourcebook. New York: Greenwood Press.

V.V. A.A. (1992): The Challenge of feminist biography: writing the lives of modern American women. Urbana: University of Illinois Press.

V.V. A.A. (1994): Gender and the academic experience: Berkeley women sociologists.Lincoln: University of Nebraska Press.

V.V. A.A. (1995): Individual voices, collective visions: fifty years of women in sociology. Philadelphia: Temple University Press.

V.V. A.A. (1995): Studying elites using qualitative methods. Thousand Oaks, Calif.: Sage Publications.

V.V. A.A. (1997): Feminist sociology: life histories of a movement. New Brunswick, London: Rutgers University Press.

V.V. A.A. (1998): Women, autobiography, theory: a reader. Madison, Wis.: University of Wisconsin Press. 
V.V. A.A. (1999:) Qualitative sociology as everyday life. Thousand Oaks: Sage Publications.

V.V. A.A. (1999): Women and autobiography. Wilmington, Del.: SR Books.

V.V. A.A. (2000): Feminism and autobiography: texts, theories, methods. London, New York: Routledge.

V.V. A.A. (2002): Doing gender, doing difference: inequality, power, and institutional change / New York: Routledge.

V.V. A.A. (2003): From girls in their elements to women in science: rethinking socialization through memory-work. New York: Peter Lang.

V.V. A.A. (2003): Our studies, ourselves: sociologists' lives and work. Oxford: Oxford University Press.

V.V. A.A. (2005): Doing women's studies: employment opportunities, personal impacts and social consequences. London; New York: Zed Books, University of Hull and the European Union.

V.V. A.A. (2006): Identity and story: creating self in narrative. Washington, DC: American Psychological Association.

V.V. A.A. (2006): The women's movement today: an encyclopedia of third-wave feminism. Westport, CT: Greenwood Press.

V.V. A.A. (2007): Reconstructing Postmodernism. New York: Nova Science Publishers.

V.V.A.A. (1991): Beyond methodology: feminist scholarship as lived research. Bloomington: Indiana University Press.

V.V.A.A. (1992): De/colonizing the subject: the politics of gender in women's autobiography. Minneapolis: University of Minnesota Press.

V.V.A.A. (1994): Autobiography and Postmodernism. Massachusetts: University of Massachusetts Press. 